\title{
Credencialismo educativo y desigualdades estructurales persistentes en la era de la modernización en España ${ }^{1}$
}

\section{Educational credentialism and persistent structural inequalities in the era of modernization in Spain}

\author{
Damián Herrera Cuesta ${ }^{2}$ \\ Universidad Nacional de Educación a Distancia, Madrid, España \\ dherrera@poli.uned.es
}

\begin{abstract}
Resumen: Es frecuente escuchar en los debates políticos que las economías desarrolladas pueden resolver los problemas de las aspiraciones individuales, la eficiencia económica y la justicia social a través de la creación de una economía basada en altas calificaciones y altos salarios. Junto a estas premisas se tiende a otorgar a la universidad un papel de especial protagonismo en el ámbito del desarrollo social y económico. Sin embargo, los bienes credenciales basados en los títulos de educación superior que dan acceso a las mejores posiciones dentro de la estructura de las ocupaciones resultan altamente costosos, tanto si adoptamos el punto de vista cultural como desde la perspectiva económica. En esta nota de investigación presentamos parte de los resultados de un estudio de más de tres años en el que se analiza la importancia de los recursos educativos y económicos disponibles por los estudiantes universitarios de diferentes orígenes socioeconómicos y sus efectos sobre la experiencia universitaria y las diferentes transiciones al mercado laboral, doce meses después de haber finalizado sus estudios.
\end{abstract}

Palabras clave: Educación superior, mercado laboral, estratificación social, clase social

${ }^{1}$ En la presente nota de investigación se revisa el trabajo de campo llevado a cabo por el autor para la realización de su tesis doctoral: Capital social, formación universitaria y empleo en la sociedad española del siglo XXI.

${ }^{2}$ Doctor en Sociología. Actualmente iinvestigador colaborador del Departamento de Sociología III (Tendencias Sociales) de la UNED. 


\begin{abstract}
It is common to hear in political debates that developed economies can solve the problems of individual aspirations, economic efficiency and social justice through the creation of an economy based on high qualifications and high salaries. Along with these premises, there is a tendency to grant the University a special role in the field of social and economic development. However, credential goods based on higher education degrees that give access to the best positions within the structure of occupations are highly costly, whether we adopt the cultural point of view or from the economic perspective. In this research note we present part of the results of a study of more than three years in which the importance of the educational and economic resources available to university students of different socioeconomic origins and their effects on the university experience and the different transitions to the labor market, 12 months after completing their studies.
\end{abstract}

Keywords: Higher education, labor market, social stratification, social class. 


\section{INTRODUCCIÓN}

Durante los últimos cuarenta años, el desarrollo tecnológico y científico ha implicado extraordinarios cambios sociales y económicos, imponiéndose en las sociedades tecnológicamente avanzadas la necesidad de aumentar el nivel educativo de su población para la realización de las funciones que conllevan los nuevos procesos productivos. En este sentido, la evolución del sistema económico capitalista ha marcado una triple tendencia. En primer lugar, tasas de población con educación superior nunca alcanzadas. En segundo lugar, una incapacidad estructural de los mercados laborales para absorber la oferta existente de graduados universitarios en aquellos puestos de trabajo para los que se han formado. Y, en tercer lugar, y paradójicamente, se ha dado un aumento del valor social asignado a disponer de un título universitario. De ahí la necesidad que sienten las familias de invertir en educación para que sus hijos tengan las mejores credenciales educativas posibles, y que les sitúen en posiciones competitivas para alcanzar un empleo ajustado a su formación.

Una triple tendencia que se corrobora con datos empíricos: la población universitaria en España, entre 1995 y 2015, ha crecido más de diez puntos (del 31,09\% al 41,87\%), siendo cada vez mayor el esfuerzo económico que hacen las familias, y que se manifiesta en el incremento de las tasas de matriculación en universidades privadas; sobre todo, en los costosos títulos de máster (del 14,28\% en 2007 al 33,65\% en 2016). Aun así, a esta población universitaria le cuesta encontrar un empleo, pues, como indican datos recientes, un 30,25\% de los jóvenes desempleados en España, entre 20 y 29 años, tenía en 2018 un título de Educación Superior (EPA, 3Tr. 2018).

El valor posicional de los títulos universitarios está determinado por las propias dinámicas del mercado de trabajo, pero también por otros factores, como el capital social y el capital económico disponibles por los individuos. Factores que han sido ampliamente estudiados desde dos grandes perspectivas teóricas. Una primera, en línea con las teorías de la modernización, muestra como una tendencia histórica en las sociedades modernas que la herencia familiar es sustituida por el logro personal como principio general de asignación de los individuos a las diferentes posiciones sociales. Según las aportaciones teóricas de los autores más relevantes de esta corriente de pensamiento: el reclutamiento meritocrático prevalece en el mercado laboral de los egresados universitarios (Hout, 1988; Breen, R. y Luijkx, R., 2004; Breen y Jonsson, 2005; Mastekaasa, 2009), pues las sociedades tecnológicamente avanzadas demandan trabajadores altamente cualificados, como señalan las teorías del capital humano (Schultz, 1961; Becker, 1983; Jovanovic, 1979; Pissarides, 2000; Acemoglu, 2002).

Una segunda perspectiva, de carácter crítico, considera que el impacto de la expansión educativa terciaria en la economía ha movilizado a los diferentes grupos sociales sensibles a 
las transformaciones que acontecen en el mundo laboral. Las familias mejor posicionadas se sienten particularmente preocupadas, dado que el título universitario ha dejado de ser suficiente para obtener una posición social de alto estatus. Estas familias cuentan con mayores recursos educativos y económicos, por lo que es plausible pensar que tratarán de mantener ventajas para sus descendientes adoptando estrategias educativas, tal y como sugiere la teoría de la desigualdad efectivamente mantenida (Effectively Maintained Inequality) (Lucas, 2001).

De acuerdo con esta teoría, en la medida que decrece la importancia del capital educativo en la competición por los mejores puestos, aumentará a su vez la importancia de otros capitales, como el capital social.

La sobreoferta de titulados en el mercado laboral conlleva que los empleadores sobrevaloren "señales adicionales". En este sentido, aspectos como la homofilia ${ }^{3}$ se han encontrado vinculados a procesos de cierre social en el acceso a los mejores puestos entre los titulados universitarios (Rivera, L., 2012, 2016). Por tanto, tal y como sugiere la teoría de la desigualdad efectivamente mantenida, es factible pensar que una reducción de la desigualdad educativa no venga acompañada, necesariamente, de una asociación directa entre educación y ocupación, entrando en juego otros mecanismos de transmisión de ventajas intergeneracionales.

La sociología de la educación y los estudios sobre estratificación social describen tres momentos críticos en los que las diferencias socioeconómicas entre los individuos pueden resultar determinantes para la movilidad social intergeneracional basada en la cualificación. En primer lugar, las transiciones educativas de los estudiantes; en segundo lugar, el abandono educativo; $y$, en tercer lugar, las transiciones al mercado laboral.

\section{PRIMERAS APROXIMACIONES EMPÍRICAS}

Antes de acometer nuestra investigación, hemos realizado unas primeras aproximaciones empíricas basadas en fuentes secundarias. Concretamente se han analizado el primero y el tercero de los puntos críticos enunciados, el acceso a la universidad y la inserción al mercado laboral de los titulados universitarios en España. Respecto al acceso ${ }^{4}$, los resultados obtenidos evidencian la existencia de una infrarrepresentación severa, no solo del estudiantado con bajo capital educativo, sino también del estudiantado con bajo capital socioeconó-

\footnotetext{
${ }^{3}$ Homofilia describe el proceso por el cual los actores tienden a establecer relaciones con otros sujetos con los que mantienen características en común (McPherson, Smith-Lovin y Cook, 2001)

${ }^{4}$ Los resultados de este análisis fueron publicados por la revista Sociología de la Educación (RASE), vol. 12, n. $^{\circ} 1$, enero de 2019.
} 
mico. En relación con el capital educativo, los universitarios cuyos padres tienen un nivel de formación por debajo de la educación secundaria, el 23,88\% en el caso del padre y el 21,45\% en el caso de la madre, se encuentran infrarrepresentados a pesar de la alta proporción de población adulta en España, con edades comprendidas entre los 40 y 60 años, que no ha superado este nivel de formación, el $45,26 \%$ de los hombres y el $42,74 \%$ de las mujeres.

\section{GRÁFICO 1}

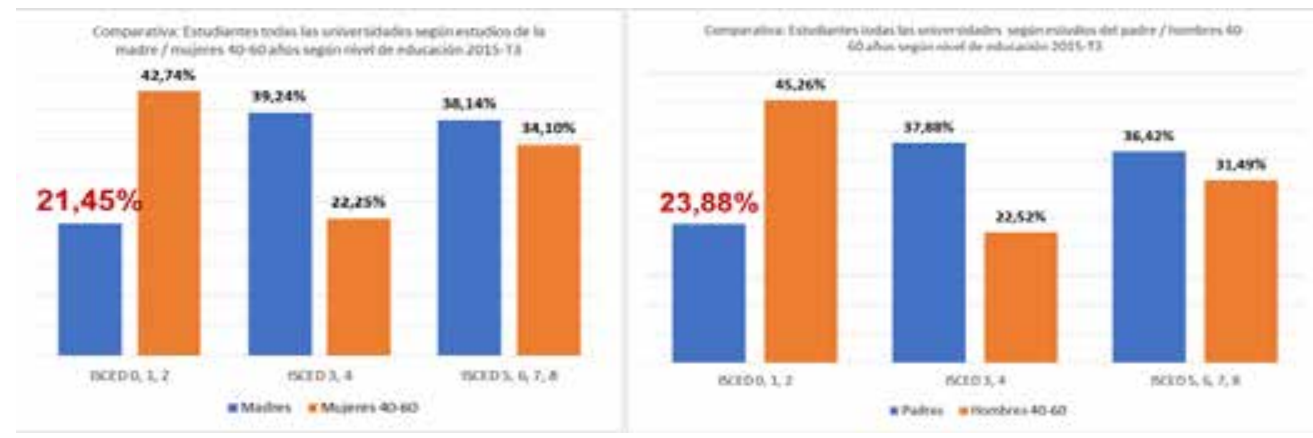

Fuente: elaboración propia a partir de datos estadísticos MECD y de la EPA, 3Tr. 2018.

Del mismo modo, en relación con el capital socioeconómico, los hijos de trabajadores no cualificados y trabajadores empleados en ocupaciones elementales apenas se hallan representados en la universidad, tan solo un $9,12 \%$ y un $7,62 \%$, según sea el padre o la madre quien se halle ocupado en alguna de estas categorías 5 .

\section{GRÁFICO 2}
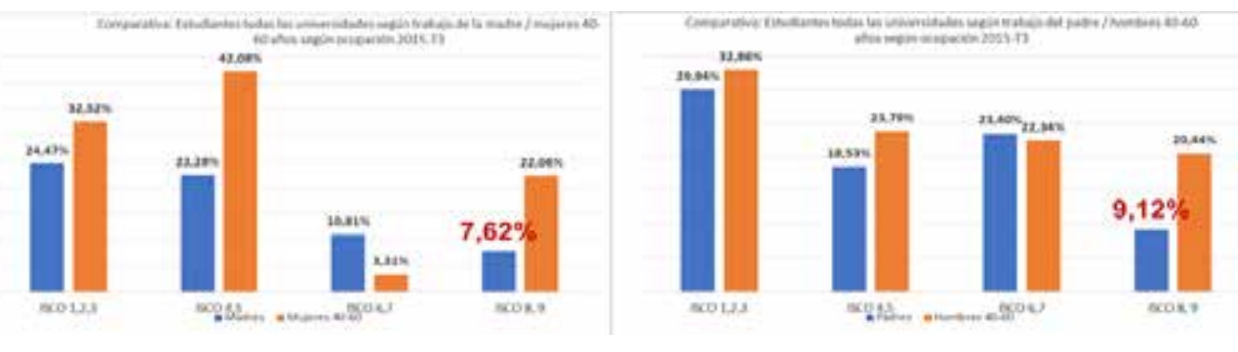

Fuente: elaboración propia a partir de datos estadísticos MECD y de la EPA, 3Tr. 2018.

5 "High White Collar" (ISCO 1, 2 o 3): directores y gerentes, técnicos y profesionales y técnicos de apoyo; "Low White Collar" (ISCO 4 y 5): empleados administrativos y de servicios; "High Blue Collar" (ISCO 6 y 7): trabajadores agrarios y de la industria, cualificados; y "Low Blue Collar" (ISCO 8 y 9): trabajadores no cualificados y trabajadores empleados en ocupaciones elementales. 
Al tiempo que se ha estudiado la composición social de la universidad española, también se ha realizado un ejercicio de aproximación a la realidad del mercado laboral de los egresados universitarios en España.

Respecto a la inserción de los egresados ${ }^{6}$, a través de los referentes empíricos explorados en esta investigación, comprobamos la existencia de una fuerte asimetría entre la oferta y la demanda de titulados universitarios en el mercado de trabajo español. Este desequilibrio se encuentra caracterizado por el fenómeno de la sobrecualificación. Fenómeno que en España afecta al $40 \%$ de los graduados, muy por encima de la media Europea, que se sitúa, según datos de Eurostat (2016), en torno al 24\%.

Este fenómeno, también asociado con determinadas ramas de conocimiento, viene siendo considerado por los teóricos del capital humano como un proceso temporal en las trayectorias laborales de los graduados. Sin embargo, en esta investigación, se pone de manifiesto que, en el caso de España, la sobrecualificación responde mejor a causas estructurales que a causas coyunturales. Apenas un $6 \%$ de los titulados españoles sobrecualificados en el año 2000 consigue salir de esta situación quince años después, en 2015. Del 37\% con 20 y 24 años en el año 2000 al 31\%, ya con 40 y 44 años de edad al final del periodo (ver Gráfico 3).

\section{GRÁFICO 3}

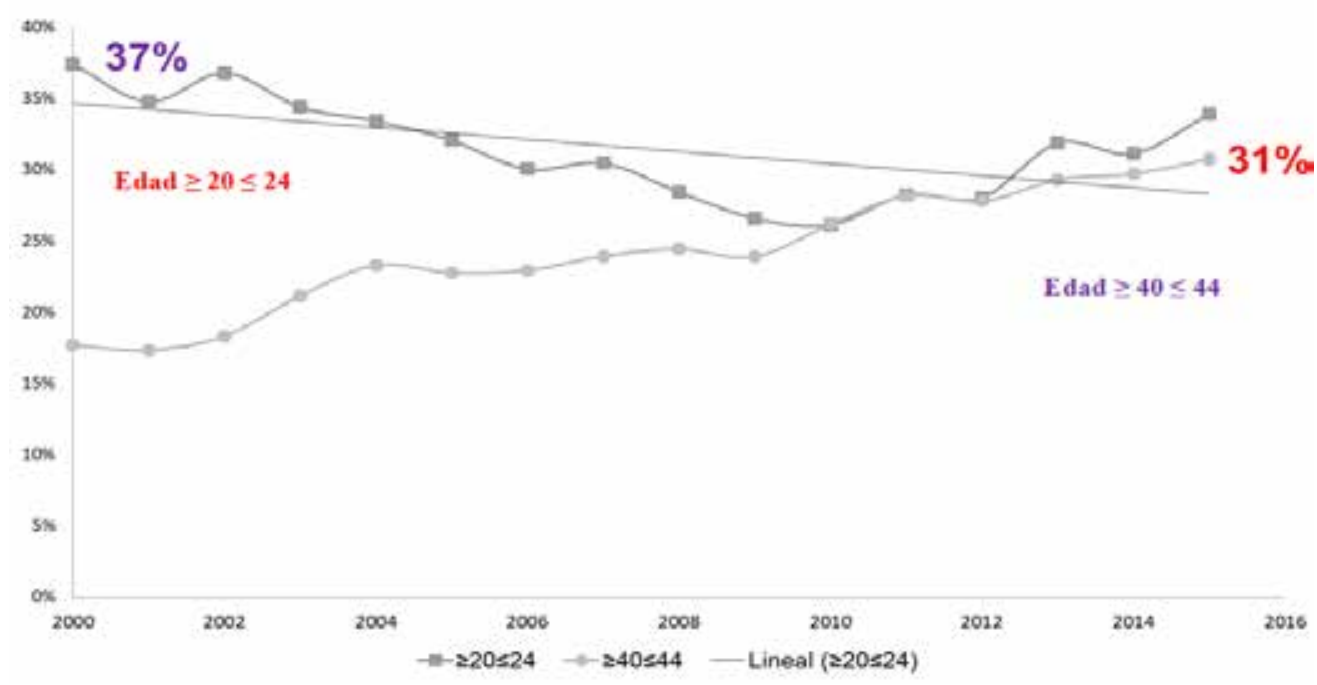

Fuente: elaboración propia a partir de datos estadísticos de la EPA.

${ }^{6}$ Los resultados de este análisis han sido recogidos por la revista Sociología del Trabajo, n. ${ }^{\circ} 89$ (2017). 


\section{METODOLOGÍA}

Analizar detenidamente la inserción laboral de los titulados universitarios españoles mediante casos concretos con el fin de determinar si la expansión de la educación superior y una mayor cualificación de la población activa está siendo en España un factor de igualdad social y de progreso conlleva diseñar un proceso de investigación, articulado en dos fases diferenciadas y que ha requerido de la utilización de técnicas cualitativas y cuantitativas de investigación social.

En la primera, se realizaron 72 entrevistas semiestructuradas, cara a cara, con estudiantes procedentes de diferentes contextos socioeconómicos que se encontraban cursando su último año de estudios en alguno de los tres niveles de educación superior — grado, máster o doctorado-, y que estudiaban en universidades públicas y privadas, localizadas en dos grandes urbes, Madrid y Barcelona.

En esta fase, los estudiantes fueron preguntados, entre otras cuestiones, sobre las razones que los llevaron a tomar la decisión de realizar estudios superiores, por qué eligieron su universidad y qué les motivó en la elección de sus estudios.

Una segunda fase consistió en el seguimiento de los estudiantes a través de un cuestionario online, diez-doce meses después de haber finalizado los estudios, con el fin de registrar los resultados de inserción al primer empleo.

Los criterios utilizados para el tratamiento de la información recogida en el trabajo de campo se agruparon en las siguientes categorías analíticas: esquema de clases, actitudes motivacionales hacia los estudios universitarios y motivaciones para la elección de estudios.

En primer lugar, se ha clasificado a los estudiantes en función de la posición socioeconómica y el capital educativo familiar, en posición alta, media y clases populares. Como puede observarse en la Tabla 1, por un lado, gran parte de los estudiantes consultados se encontraban en posiciones altas y medias, y, por otro lado, también vemos que la mayoría estudiaban en universidades públicas.

En segundo lugar, se han diferenciado las actitudes motivacionales de los universitarios entrevistados hacia los estudios, estableciéndose dos modelos: por un lado aquellos que muestran motivaciones normalizadas, esto es, cuando ir a la universidad es lo normal en la familia y se entiende como algo "natural"; y, por otro, aquellos que muestran motivaciones legitimadas, es decir, cuando ir a la universidad es el resultado de una elección, por lo que de algún modo tienen la necesidad de justificarla. Por regla general, estos últimos vienen a ser el primer miembro familiar que realiza estudios superiores.

En tercer lugar, respecto a las motivaciones básicas en la elección de estudios, hemos distinguido el interés instrumental (búsqueda de la rentabilidad laboral y económi- 
TABLA 1

Estudiantes según posición socioeconómica

\begin{tabular}{lccc}
\hline \multirow{2}{*}{ Clase } & \multicolumn{2}{c}{ Tipo de Universidad } & Total \\
\cline { 2 - 3 } & Pública & Privada & \\
\hline Posición alta & 10 & 13 & 23 \\
Posición media & 11 & 9 & 20 \\
Clases populares & 27 & 2 & 29 \\
& 48 & 24 & 72 \\
\hline
\end{tabular}

Fuente: elaboración propia a partir de la información obtenida en el trabajo de campo

ca de la formación) del interés expresivo, es decir, estudiar por el deseo de conocimiento en sí mismo.

\section{RESULTADOS}

\section{Primera fase}

Los resultados de campo en esta fase muestran, en primer lugar, una relación fuerte entre la existencia de capital educativo en el seno familiar y una actitud normalizada de los estudiantes hacia los estudios superiores (67\%). Los estudiantes que proceden de familias con mayores recursos socioeconómicos suelen contar, a su vez, con un capital educativo alto (54\%) (ver Tabla 2).

TABLA 2

\begin{tabular}{lccc}
\hline & Capital Cultural Alto & Capital Cultural Medio & Capital Cultural Bajo \\
\cline { 2 - 4 } Normalizado & $67 \%$ & $23 \%$ & $5 \%$ \\
Legitimado & $12 \%$ & $6 \%$ & $82 \%$ \\
\hline & Posiciones Altas & Posiciones Medias & Clases Populares \\
\cline { 2 - 4 } & $54 \%$ & $39 \%$ & $8 \%$ \\
Normalizado & $6 \%$ & $18 \%$ & $76 \%$ \\
\hline
\end{tabular}

Fuente: elaboración propia a partir de la información obtenida en el trabajo de campo.

Contar con este tipo de capital (educativo) es un recurso que influye positivamente en las motivaciones y disposiciones de estos estudiantes hacia la educación superior. 
También, de manera determinante, sobre la adaptación al ambiente universitario, favoreciendo el éxito social y académico en este medio, tal y como se recoge en la siguiente muestra de verbatim de las entrevistas realizadas.

"Obviamente, que mi padre tenga estudios superiores y que sea una persona de negocios incita a que la educación que hemos recibido tanto yo como mis hermanos nos haya hecho llegar a la Universidad, y sobre todo porque, no sé, las aspiraciones que uno tiene y que haya sido bueno en los estudios. No sé. Nunca me he planteado no ir a la Universidad. Siempre he estado seguro (...) Siempre he pensado que ir a la Universidad era el camino que seguir para todo el mundo." (P51. A., 23 años, Estudiante de Grado en ADE. Univ. Pública, Madrid. Clase Social, posiciones medias (IIa); Cap. Cult. Univ. Alto)

Frente a estos estudiantes encontramos otro grupo para los que llegar a la universidad no es sino el resultado de una decisión condicionada. Estos jóvenes son conscientes de los limitados recursos disponibles por sus familias, y solo el buen rendimiento académico en los niveles preuniversitarios les permite obtener las ayudas económicas que necesitan para poder ingresar en la universidad y mantenerse en ella. De hecho, es exclusivamente en este grupo donde los criterios selectivos (meritocráticos y económicos) para la realización de estudios superiores se hacen funcionalmente efectivos.

\section{"...al no haber nadie en la familia que tuviese estudios} universitarios, como que me apoyaban muchísimo. Y me decían, sigue hacia adelante, haz tu carrera, licénciate. En eso tuve grandes apoyos, y, en lo que es la carrera, la verdad es que siempre he sido buena estudiante. $\mathrm{Me}$ ha gustado estudiar. Siempre he tenido buenas calificaciones. No supernotas, no todo sobresaliente, pero notables y eso, sí." (P47. A., 24 años. Estudiante de Máster. Univ. Pública. Madrid. Clases Populares; Cap. Cult. Univ. Bajo)

Respecto a la elección de estudios, las motivaciones expresivas se distribuyen de forma desproporcionada cuando consideramos las titulaciones con mayor demanda en el mercado y la posición socioeconómica de los estudiantes. Mientras que los estudiantes de clase alta y media manifiestan motivaciones expresivas hacia titulaciones con 
buenas salidas laborales (ADE, Derecho, ingenierías), la mayoría de los estudiantes entrevistados que manifiestan este tipo de motivaciones hacia carreras consideradas "difíciles" - Matemáticas o Física-, o hacia aquellas, dentro de las ramas blandas, con peores expectativas en el mercado laboral, proceden de las clases Populares (63\%) (ver Gráfico 4).

GRÁFICO 4

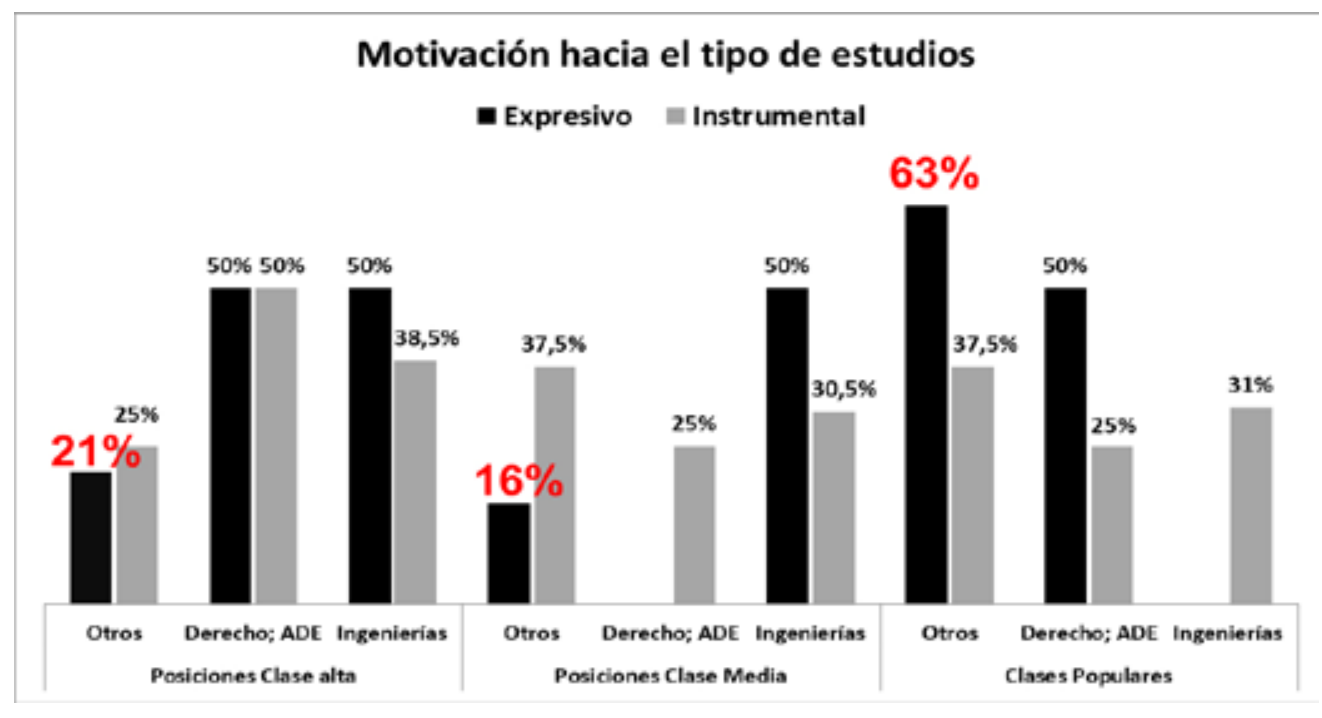

Fuente: elaboración propia a partir de la información del trabajo de campo.

A diferencia de los estudiantes de las universidades públicas, para los estudiantes de las universidades privadas entrevistados el factor más importante a la hora de elegir universidad es el prestigio de esta como capital social mediador para el empleo, desplazando los restantes motivos a un plano secundario.

Siempre me han dicho que de aquí debería salir con trabajo. Que te vienen a buscar las empresas. Aquí no vas tú a las empresas, sino que las empresas vienen a ti. Y esta es una gran motivación porque no te preocupas tanto (...) porque tienes un futuro laboral asegurado nada más salir. (P120. E., Estudiante de Ingeniería. Univ. Privada. Barcelona. Clase Posiciones Altas (Ia); Cap. Cult. Univ. Alto) 


\section{Segunda fase}

En la segunda fase analizamos los resultados de inserción al mercado laboral doce meses después de finalizar los estudios. Los datos recogidos muestran una baja segmentación de los egresados universitarios si atendemos a su situación laboral. La proporción de estudiantes que se encontraban ocupados en el momento de la encuesta fue del $83,8 \%$. Las mujeres presentaban mayor proporción de empleabilidad (88,5\%) que los hombres (81\%) (ver Gráfico 5).

\section{GRÁFICO 5}

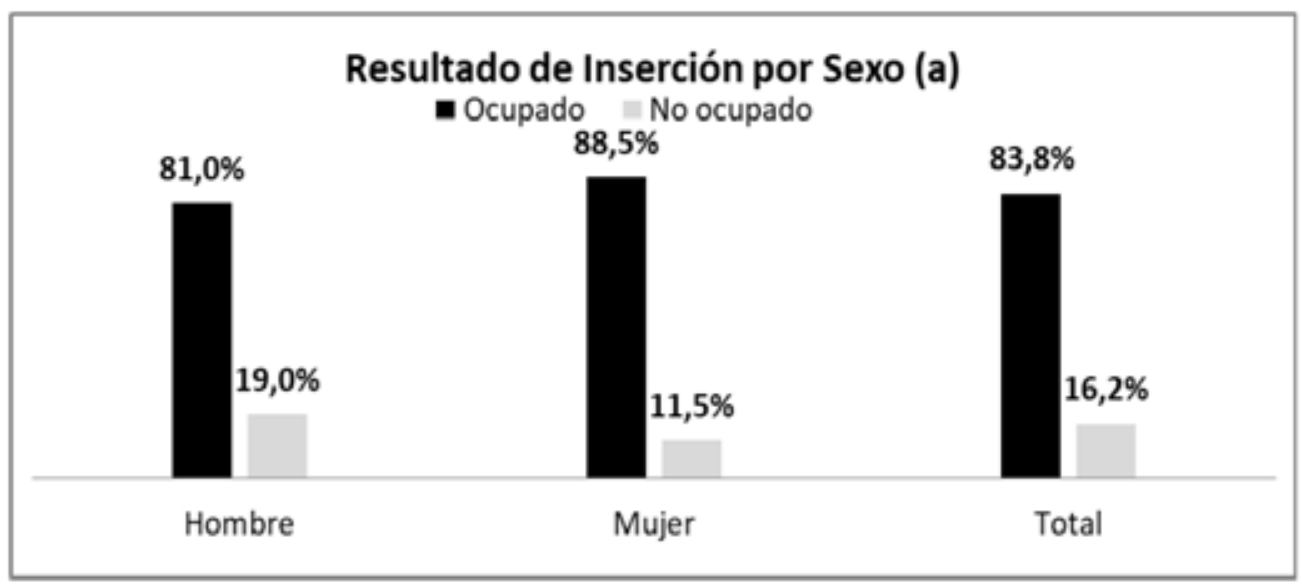

Fuente: elaboración propia a partir de la información del trabajo de campo.

Sin embargo, los datos muestran una fuerte segmentación según la categoría ocupacional en que se encontraban empleados estos estudiantes. Solo el 54,6\% de los estudiantes de la muestra se empleaba dentro de categorías ocupacionales ajustadas a su nivel y tipo de formación: 5,5\% "directivos" y 49,1\% "técnicos profesionales, científicos e intelectuales" (ver Gráfico 6).

También hallamos fuertes segmentaciones por "tipo de contrato", una vez han sido controladas las variables "sexo" y "titulaciones" (ver Gráfico 7).

En el primer caso, ellas experimentan en mayor medida que ellos la temporalidad y la precariedad laboral (56,5\% frente al 31,3\%), y se emplean en mayor número como trabajadoras no cualificadas. Un $21,4 \%$ de ellas se ocupan en estas categorías, frente al $9,4 \%$ de los hombres, como vemos en el Gráfico 8. 


\section{GRÁFICO 8}
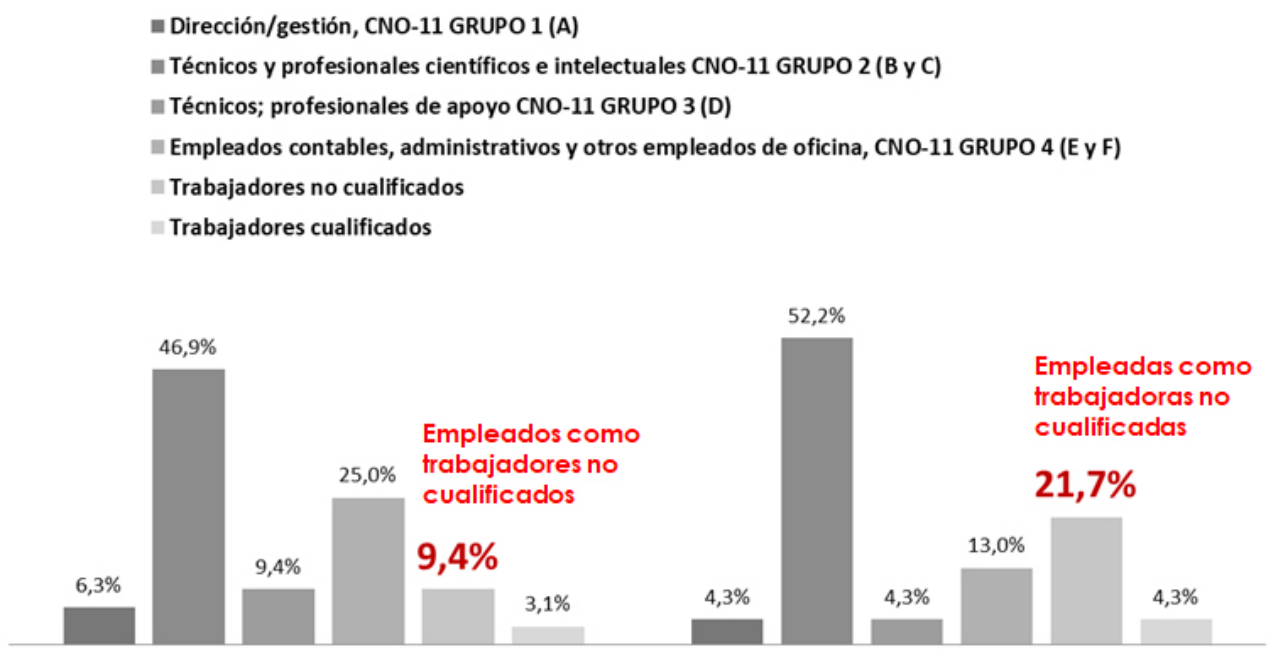

Hombre

Mujer

Fuente: elaboración propia a partir de la información del trabajo de campo.

Según la rama de conocimiento, los resultados muestran que no todas ofrecen las mismas oportunidades de éxito en el mercado laboral. Teniendo en cuenta la estabilidad en el primer empleo, las titulaciones con más éxito son las diferentes ingenierías (40\%), los títulos relacionados con las finanzas y el mundo de la empresa $(44,4 \%)$, la carrera de Medicina dentro de las Ciencias de la Salud (50\%) y Derecho, en la rama de las Ciencias Sociales (40\%) (ver Gráfico 9). En el lado contrario, con transiciones al mercado laboral más inestables, se encuentra la rama de Arte y Humanidades (50\%), así como la mayoría de los egresados con titulaciones dentro de la rama de Ciencias (nivel de grado) (61,5\%).

Los datos hasta aquí apuntados, por tanto, vienen a responder afirmativamente a la hipótesis de que la inserción de los titulados universitarios en el mercado de trabajo habría dejado de corresponderse con la norma tradicional. Norma según la cual el título universitario garantizaba la ocupación en puestos de trabajo dentro de los primeros segmentos del mercado laboral en España. Con ello, al analizar el mercado laboral de los titulados universitarios encontraríamos segmentaciones internas e, incluso, situaciones contradictorias como "sobrecualificación", incluyendo condiciones laborales marcadas por la precariedad.

En esta segunda fase, además de la inserción al primer empleo y sus características, analizamos la relación existente entre la posición socioeconómica y los resultados laborales de los egresados universitarios entrevistados (ver Gráfico 10). 
GRÁFICO 9

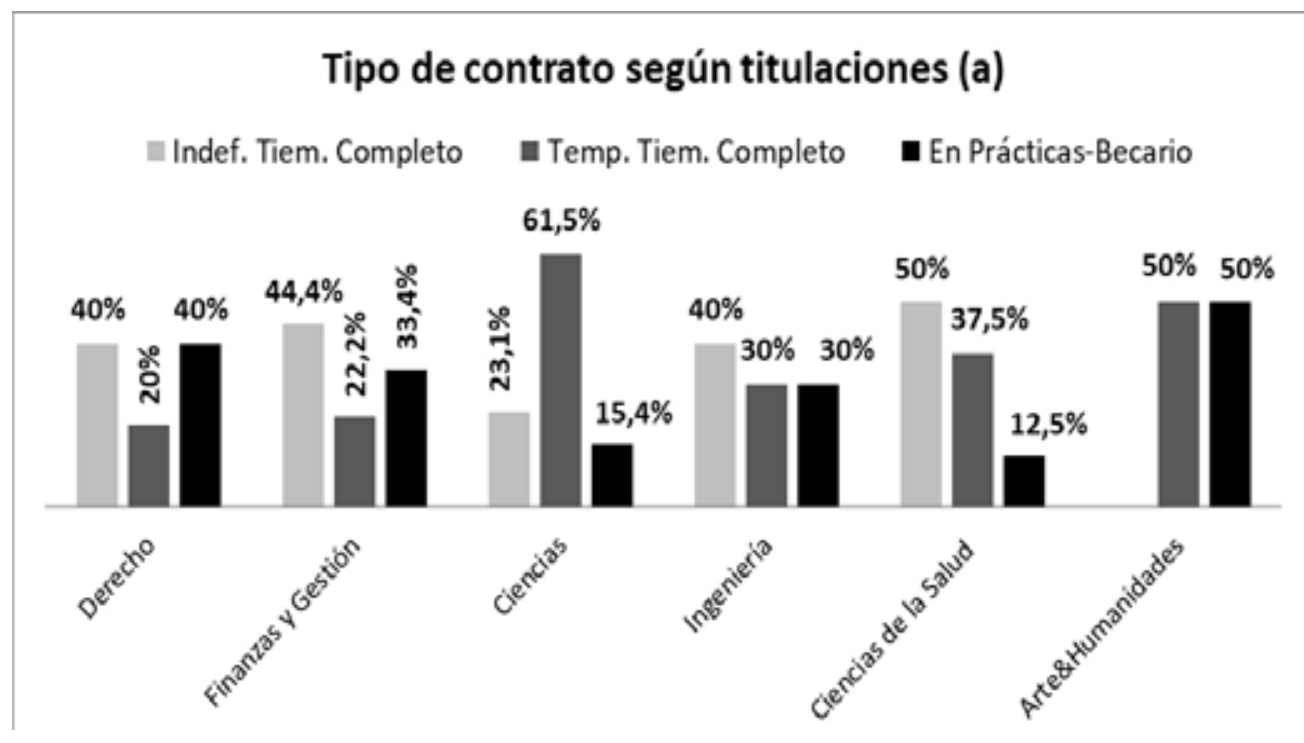

Fuente: elaboración propia a partir de la información del trabajo de campo.

Únicamente los egresados procedentes de posiciones altas se ocupaban en la categoría de "dirección y gestión" (15,8\%). También se ocupaban en mayor medida como "empleados contables" (31,6\%).

Por su parte, los universitarios pertenecientes a las posiciones de clase media reproducen las categorías ocupacionales de sus progenitores, siendo los que mayormente se encontraban ocupados dentro de la categoría "técnicos, profesionales científicos e intelectuales" (70\%).

Finalmente, los universitarios pertenecientes a las clases populares experimentaban en mayor grado la sobrecualificación, siendo egresados de este grupo los únicos que se ocupaban como "trabajadores no cualificados" (30,8\%).

Estos resultados vienen a corroborar la hipótesis según la cual se propone la existencia de una relación significativa entre la posición socioeconómica de los egresados universitarios y las características de inserción al primer empleo.

\section{CONCLUSIONES}

Sin duda, el esfuerzo que ha requerido la complejidad metodológica aquí expuesta se ha visto recompensado por la riqueza de los datos recogidos, permitiendo el análisis 


\section{GRÁFICO 10}

\section{Categoría ocupacional y posición socioeconómica}
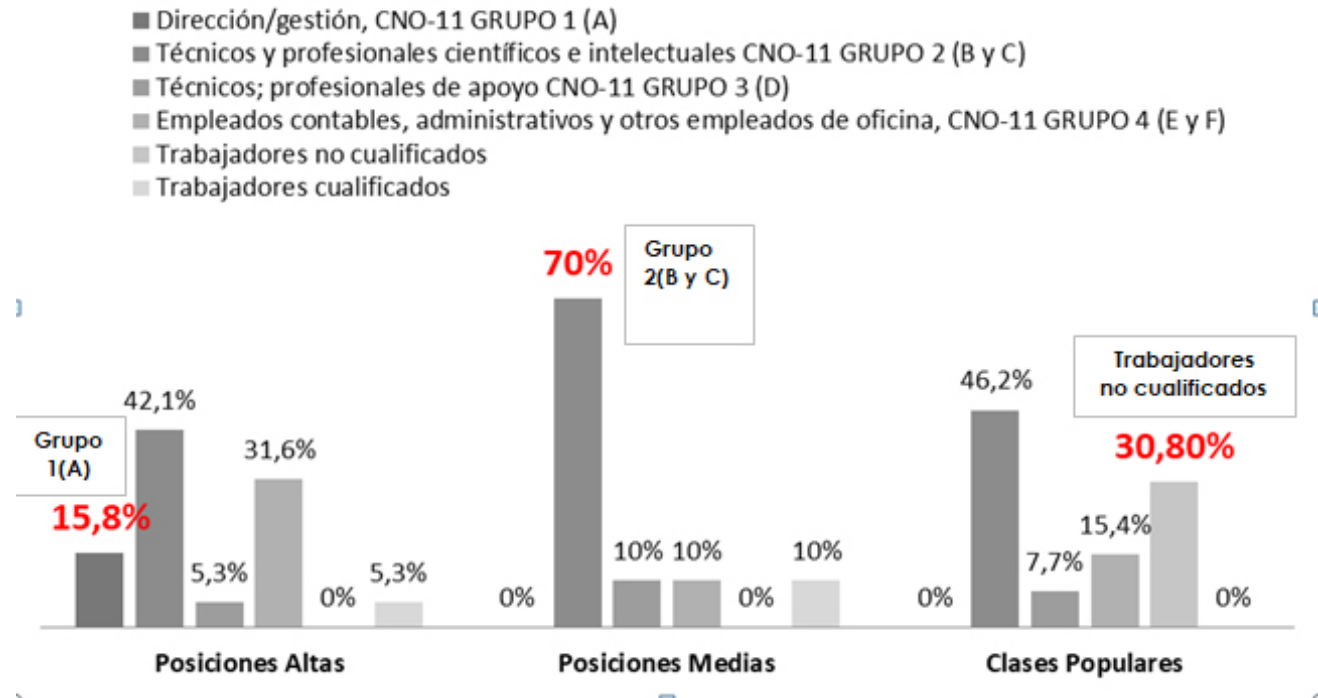

Fuente: elaboración propia a partir de la información del trabajo de campo.

longitudinal y la introducción de programas de evaluación y mejora continua del proceso investigador. Proceso aún abierto, proyectándose el seguimiento de las trayectorias del grupo de estudiantes participantes durante los próximos cuatro años, hasta 2022.

En primer lugar, cabe reseñar el alto número observado de titulados universitarios ocupados en empleos cuya cualificación no requiere el nivel de formación alcanzado, proporciones que doblan la media europea. Situación que, sin duda, pone de relieve el deficiente grado de modernización de la economía española, incapaz de absorber la oferta laboral altamente cualificada que se forma en sus universidades.

Respecto al peso de la influencia de las desigualdades estructurales en la inserción al mercado laboral de los titulados universitarios en España durante la segunda década del siglo XXI, encontramos que disponer de recursos socioeconómicos significativos favorece la obtención de un título de posgrado competitivo, e incrementa las posibilidades de ocupar puestos de trabajo de mejor calidad y en los mejores destinos dentro de la estructura ocupacional, los de "dirección y gestión".

En sentido contrario, carecer de estos recursos socioeconómicos incide, negativamente, en las oportunidades de ir más allá del nivel de grado universitario, limitando las posibilidades de diversificar competencias, lo que genera que estos estudiantes posean 
una empleabilidad de bajo nivel competitivo, al tiempo que se incrementa la probabilidad de experimentar desajustes y sobrecualificación en el mercado laboral.

\section{BIBLIOGRAFÍA}

Acemoglu, D. (2002). «Technical Change, Inequality, and the Labor Market». Journal of Economic Literature, 40(1): 7-72.

Becker, G. (1983). El capital humano: Un análisis teórico y empírico referido fundamentalmente a la educación. Madrid. Alianza.

Breen, R. y Jonsson, J. (2005). "Inequality of opportunity in comparative perspective: Recent research on educational attainment and social mobility". Review of Sociology, 31:1, 223-243 https://doi.org/10.1146/annurev.soc.31.041304.122232

Breen, R. y Luijkx, R. (2004). "Social mobility in europe between 1970 and 2000", en R. Breen, Social Mobility in Europe, pp. 37-75

Eurostat (2012). Data on Education matching of developed generic competences of graduates in higher education with labour market needs, 165. EACEA

Eurostat. Estadísticas de transición de estudios al trabajo. Datos de septiembre de 2012. Recuperado de:

http://ec.europa.eu/eurostat/statistics-explained/index.php?title=Archive:School-to-work_ transition_statistics\&oldid $=119120$

Eurostat. Estadísticas de empleo y demanda de trabajo. Recuperado de: http://ec.europa. eu/eurostat/statistics-explained/index.php/Employment_and_labour_demand\# Over-qualification_rate

Eurostat. Estrategía 2020. Documento recuperado de: https://ec.europa.eu/info/businesseconomy-euro/economic-and-fiscal-policy-coordination/eu-economic-governancemonitoring-prevention-correction/european-semester/framework/europe-2020strategy_es

Hout, M. (1988). "More universalism, less structural mobility: The american occupational structure in the 1980s". American Journal of Sociology, 93(6), 1358-1400.

Instituto Nacional de Estadística (INE). Clasificación Nacional de Ocupaciones (CNO11). Documento recuperado de: Clasificación Nacional de Ocupaciones (CNO-11) Instituto Nacional de Estadística (INE). Encuesta de población activa (EPA). Documento recuperado de: http://www.ine.es/dyngs/inebase/es/operacion.htm?C=Estadistica_ $C \&$ cid $=1254736176918 \&$ menu $=u l$ tidatos $\& i d p=1254735976595$

Instituto Nacional de Estadística (INE), 2016T4. Documento recuperado de: http:// www.ine.es/jaxiT3/Datos.htm?t=6393 
Instituto Nacional de Estadística (INE), 2018T3. Documento recuperado de: https:// www.ine.es/dyngs/INEbase/operacion.htm?c=Estadistica_C\&cid=1254736176918 $\&$ menu=resultados\&secc $=1254736195129 \&$ idp $=1254735976595$

Jovanovic, B. (1979). «Job Matching and the Theory of Turnover». Journal of Political Economy, 87(5): 972-990.

Lucas, S. (2001). "Effectively maintained inequality: Education transitions, track mobility, and social background effects". American Journal of Sociology, 106(6), 16421690.

Mastekaasa, A. (2011). «Social Origins and Labour Market Success-Stability and Change over Norwegian Birth Cohorts 1950-1969». European Sociological Review, 27(1): 1-15.

Ministerio de Educación, Cultura y Deporte. Estadísticas universitarias. Entrada al sistema universitario. Acceso a la Universidad 2017. Última consulta: julio de 2018. Documento recuperado de: https://www.educacion.gob.es/educabase/menu.do?Type= pcaxis\&path=/Universitaria/Indicadores/2017/1_Acceso\&file=pcaxis\&l=s0

Pissarides, C. A. (2000). Equilibrium unemployment theory. MIT Press.

Rivera, L. (2012). "Hiring as Cultural Matching: The Case of Elite Professional Service Firms". EE. UU. American Sociological Review, 77(6): 999-1012.

- (2016). Pedigree: How elite students get elite jobs. Princeton University Press.

Schultz, T. (1961). "Investment in Human Capital". The American Economic Review, (51)1. 